\title{
The Impact of Information Technology Facility and Knowledge Management Policy on Product Improvement for Dire Dawa National and Ture Cement Factories in Ethiopia 2015; Cross-sectional Survey Method
}

\author{
Yeshiareg Temtime (BSc, MSc) Worku Jimma (BSc, MSc, Phd candidate ) \\ Department of Information Science, Jimma University, Jimma, Ethiopia
}

\begin{abstract}
Information Technology has a crucial role to play in the creation and dissemination of knowledge in a variety of organizations and information technology allows an organization to create, share, store, and use knowledge. This study identified the impact of information technology facility, policy and culture that is available in cement factories. The study also examines the relationship between information technology facility, knowledge management policy and organizational productivity that exercise in Dire Dawa national and Ture cement factories. Qualitative and quantitative approach was used to investigate the existing gaps that may likely be initiated by different contextual attributes. To carry out this investigation a descriptive research method was used. Purposive and simple random sampling was used for selected 143 office employees. Questionnaire, interviews and observation check list were used to gather data. The result of present study showed that the selected cement factories have organizational and knowledge management culture with existing policy. ICT facility give strength for organizational productivity and also ICT facility with knowledge management policy available in the factories have grate contributions on organizational productivity. The limited functionality of ICT facility, the non availability of knowledge management policy and limited capacity knowledge expert are problems that hinder organizational productivity in the factories.
\end{abstract}

Keywords: ICT facility, Organizational Productivity, Available Knowledge Management policy

DOI: $10.7176 / \mathrm{IKM} / 10-7-04$

Publication date:October $31^{\text {st }} 2020$

\section{Introduction}

Fischer (2000) study identifies KM for manufacturing industry as a specific sub-domain, That knowledge was centered on specific product(s), processes and technologies and addressing, good transparency of business processes and products, great common business interest potentially leading to a solid legal background for knowledge sharing.

It also concern on increased motivation of management and employees, transition from traditional manufacturing to knowledge driven companies, actors for internal knowledge management systems in double role that was source and user of knowledge from shop-floor workers, to high specialists, top managers.

The diffusion of technology is promoted by openness to international competition and efficiency is also closely linked to competition as weak competition may result in management and workers appropriating rents in the form of organizational slack and overstaffing (OECD, 1996). Technology can support KM in two ways: firstly by providing the means to organize, store, retrieve, disseminate and share explicit knowledge and information rapidly around the organization and around the world and secondly by connecting people with people through collaborative tools to capture and share tacit knowledge (Jain 2007).

According to Martin 2008 study the most common technology applications area for KM are Groupware that is messaging and email, document management, workflow, data warehouse, multi-media repositories, intranets and portals, information retrieval technologies and search engines, business modeling and intelligent agents can be categorized by content management that is in the form of knowledge transfer/sharing and collaboration or by using distributive and collaborative technologies.

Implanting KM system in any scale without technology is extremely difficult, but the technology itself does not make the KM system work, it can facilitate and enable connections and communications but it will not make them happen (Wormell 2004). The result of Webster 2007study shows that technology can improve knowledge flows, but cannot guarantee them, Even the most successful technological solutions can be frustrated by a lack of time and motivation for knowledge sharing, and inability to truly capture tacit knowledge and use this knowledge effectively. Mills and Smith, 2011 study about technology element of knowledge infrastructure comprises the information technology systems that enable the integration of information and knowledge in the organization as well as the creation, transfer and storage of organization's knowledge assets. According to Mills and Smith the role of information technology infrastructure is important, because it enhances knowledge access, transfer and facilitates the knowledge sharing inside the organization.

Organizational culture is not only specifies what knowledge is valued, but also what knowledge must be kept 
inside the organization for sustained innovative advantage (Long, 1997). There are four comprehensive ways in which culture influences the behaviors of knowledge creation, sharing, and use. First, culture shapes assumptions about what knowledge is and which knowledge is worth managing. Second, culture establishes relationships between individual and organizational knowledge, determining who is expected to control specific knowledge, as well as who must share it and who can hoard it. Third, culture creates the context for social interaction that determines how knowledge will be used in particular situations. Finally, culture shapes the processes by which new knowledge with its accompanying uncertainties is created, legitimated, and distributed in the organization (DeLong and Fahey, 2000).

\section{Problem statement}

The goal of KM Policy is dissemination and sharing of the Company's existing knowledge, continuous learning, and cultural exchange, enhance operational efficiency through the proper use of intellectual capital, always furthering the interests of the Company and of the companies belonging to the group of companies of which the Company is the controlling entity, within the meaning established by law (the Group), and without prejudice to specific policies that may be established at particular companies of the Group (IBERDROLA,2015).

Even if manufacturing industry have effective KM strategies and adequate ICT infrastructure but the major difficulty faced by those industries operated both in the private and public sector today which was finding a way to overcome those softer cultural and behavioral obstacles that lay in the way of successful implementation in KMP that includes: knowledge creation, knowledge sharing, knowledge acquisition, knowledge preservation and knowledge application. Most of the time manufacturing industries not clearly identify factors that affect the implementation of KMP.

In the economic and commercial sector, ICTs as one of the main driving forces have helped to creates borderless world, a feature of which was global competition among organizations. To survive in the face of such global competition, organizations increasingly depend on their ability to transform information into knowledge as the basis of competitiveness, decision-making and the production of new products and services, identify the impact of ICT on the implementation of knowledge in organization was the main problem faced by this research (Sarrafzadeh,2008). This area need research in selected cement factories.

According to Ruggles, 1998 the main barriers to implement $\mathrm{KM}$ in the manufacturing industry were all employees, top manager with leadership related issues and culture that inhibited knowledge sharing and such a habit is expected to exist in Dire Dawa national and Ture cement factories have factors and policy that affect knowledge sharing need research. Many organizations today are giving much emphasis on the adoption of KM policy and the objective of KM policy is not to manage all knowledge, but to manage the knowledge which is most essential to the development of organizations, knowledge available both in Dire Dawa national and Ture identify by research (Parikh M, 2001). The study found it important to identify the relationship between ICT facility and KM policy with organizational productivity in Ethiopia manufacturing industries not yet identify by research. Specifically the paper sought to determine the current status of Knowledge Management policy in Ethiopia manufacturing enterprises need examine organizational and knowledge management culture that influence organizational productivity and ICT facility that support and available organizational productivity.

\section{Research questions}

1. What is the existing policy and practices to support organizational productivity in the cement factories?

2. What is the organizational culture that supports organizational productivity in the cement factories?

3. What are ICT facilities that are available in the cement factory for enhancing organizational productivity?

\section{Objectives of the Study}

The main objective of this study is to assess the impact of information technology facility and knowledge management policy on product improvement in Dire Dawa National and Ture cement factories and the specific objectives of this research are as follows:-

$>$ To investigate the existing policy and practice that support organizational productivity in the cement factories.

$>$ To investigate the existing culture that support organizational productivity in the cement factories.

$>$ To identify ICT facilities that is available in the cement factory for enhancing organizational productivity.

\section{Significance of the study}

Muhammad (2011) in his study indicated that KM was one of the significant factors which contribute to organizations' struggle to improve their performance. This study is also very significant in a number of ways that include contributing to identifying KM policy, organizational culture and practice of Dire Dawa National and Ture cement factories help top management of the factories have clear understanding about KM policy and ICT facility that help for KMP in the factories and also takes the necessary measures to improve individual and organizational 
competitiveness.

The significance of the present research includes improvement of productivity by proper application of KM policy and ICT facility available in the factories for KMP. The other significance of this study is employee's understanding about KM policy within organizational information context by identifying and defining the main attributes of KMP by pointing out the critical factors of KMP and find suitable ways of management of knowledge in that context. If employees have a better understanding about the effect of KM policy on decision making and increase productivity in manufacturing industry also create awareness about the use of KM policy in the cement industry. Effective use of ICT facility helps to remove resource constraint, decrease cost of products and create innovative applications for mature products that make companies move ahead of their competitors.

\section{REVIEW OF RELATED LITERATURE}

\section{Knowledge management practice on ICT facility}

Information Technology has a crucial role to play in the creation and dissemination of knowledge in a variety of organizations and information technology allows an organization to create, share, store, and use knowledge. The focus of KM has moved from technology towards human expertise, including recognition of the importance of tacit knowledge, other disciplines and departments have become increasingly involved (Koenig \& Srikantaiah 2002). The degree of competition in a particular country or sector is often considered to be among the most important of such factors, since a lack of competition reduces the pressure on firms to incorporate better technology, remove organizational slack and improve productivity performance. (OECD, 1996).

According to Martin 2008 study the most common technology applications area for KM are Groupware that is messaging and email, document management, workflow, data warehouse, multi-media repositories, intranets and portals, information retrieval technologies and search engines, business modeling and intelligent agents can be categorized by content management that is in the form of knowledge transfer/sharing and collaboration or by using distributive and collaborative technologies.

Kazemi and Allahyari (2010) points out that KM technologies and software application provide the right information to the right people at the right time. To maximize the value of knowledge, appropriate information system infrastructure is required to facilitate sharing, transforming and capturing knowledge. According to Ajmal, Helo and Kekale (2010) the use of strong information technology for organization is facilitates communication, collection, and re-use of knowledge. KM system should also facilitate communication and knowledge exchange across different organizational entities that share knowledge and experiences (Du Plessis, 2007).

Géraud in 2005 studied the common misconception about KM in the organization that is KM is mainly about technology those getting an intranet, linking people by e-mail, compiling information databases but technology is often a crucial enabler of KM it can help connect people with information, and people with each other, but it is not the solution and it is vital that any technology used fits the organization's people and processes otherwise it will simply not be used.

\section{The impact of organizational policy and culture on organizational productivity}

The goal of KM Policy is dissemination and sharing of the Company's existing knowledge, continuous learning, and cultural exchange, enhance operational efficiency through the proper use of intellectual capital, always furthering the interests of the Company and of the companies belonging to the group of companies of which the Company is the controlling entity, within the meaning established by law (the Group), and without prejudice to specific policies that may be established at particular companies of the Group (IBERDROLA,2015).

KM program tend to have both collecting and connecting dimension, the collecting dimension involves linking people with information, it relates to the capturing and disseminating of explicit knowledge through information and communication technologies aimed at codifying, storing and retrieving content, which in principle continuously updated through computer networks. Through such collections of content, what is learned is made readily accessible to future users.

The connecting dimension involves linking people with people specifically people who need to know with those who do know, and so enhancing tacit knowledge flow through better human interaction, so that knowledge is diffused around the organization and not just held in the heads of few. Connecting is necessary because knowledge is embodied in people, and in the relationships within and between organizations. Information becomes knowledge as it is interpreted in the light of the individual's understandings of the particular context.

skills directories and expert directories, searchable online staff directories that give much more detail about who does what and who knows what are examples of connecting dimension and collaborative working, communities of practice networks of people with a common interest, and various socialization activities designed to support knowledge flows are connecting dimension. According to his study organization that focuses entirely on connecting, with little or no attempt at collecting, can be very inefficient.

Such organizations may waste time in reinventing wheels. The aim of integrated KM program is managing knowledge, by combining the benefits of both approaches and achieving a balance between connecting individuals 
who need to know with those who do know, and collecting what is learned as a result of these connections and making that easily accessible to others (Géraud,2005).

\section{RESEARCH METHODOLOGY}

Dire Dawa National and Ture cement factories were one of the cement factories in Ethiopia. It is located at 515 kilometers away from the capital city, Addis Ababa to the east in the Dire Dawa administrative region.

\section{Research Methods}

The researcher used cross sectional survey research method for this study. The study was concerned with investigating KMP for product improvement in the case of Dire Dawa national and Ture cement factories. Cross sectional survey research method because it is best for provides a relatively simple and straightforward approach to the respondents' attitudes, values, beliefs and motives; and it allows high amount of data standardization.

\section{Sampling techniques}

The sampling technique used for this study was purposive and simple random sampling to arrive at the study target population. First purposive sampling method was used for selecting managers, MIS/HR and ICT director for the purpose of interview and simple random sampling method was used for identifying the specific 120 office worker from the factories.

\section{Sample size}

Dire Dawa national and Ture cement factories has 220 total offices worker employees, from this this research was used 120 employees by doing sample size formula.

\section{Data Collection}

The methods used to collect data for this study were questionnaire, interview and observation cheek list

From different categories of each data collection methods fixed alternative questionnaire method was used to collect data from the staff and face-to-face interview method was used to collect data from ICT director and head of MIS. Detailed observation was done for the availability of ICT facility, KM policy availability at each study site. The questionnaires included nominal and likert type items.

\section{Results and discussion}

\section{ICT facilities in Dire Dawa and Ture cement factories}

ICT has emerged as one of the major tools used by corporate organizations for optimal performance because of its effective and efficient application in manufacturing industry. The elicit the contributions of ICT manufacturing industry for overall productivity and profitability, different questions were posed to the respondents on ICT facility and availability, availability of Internet connection, storage of data and access computerized data. A summary of the respondents' response is presented in table 1 below:

Table 1 ICT facilities and availability

\begin{tabular}{|l|l|l|l|}
\hline Statements & Indicators & Frequency & Percent \\
\hline Available of ICT facilities in the factories & Yes & 95 & 79.2 \\
\cline { 2 - 4 } & No & 25 & 20.8 \\
\hline \multirow{2}{*}{$\begin{array}{l}\text { Availability of internet connection in the } \\
\text { factories }\end{array}$} & Yes & 74 & 61.7 \\
\cline { 2 - 4 } & No & 46 & 38.3 \\
\hline
\end{tabular}

According to the above table $1,79.2 \%$ of the responded "ICT facility was available" in Dire Dawa national and Ture cement factories. ICT facility contains availability of Internet connection, computers available in each employees' office, technology based decision making process and usability of electronic data available in the factories. ICT facility contains lap top, desk top computer, based on "availability of Internet connection" (61.7\%) of respondent from Dawa national and Ture cement factories says that in the office computer has an Internet connection. According to respondent Internet connection, storage of data and access electronic data were indicators of ICT facility, but those indicators were different in Dire Dawa national and Ture cement factories.

Internet connection, storage of data and access electronic data were indicators of ICT facility, but those indicators were different in Dire Dawa national and Ture cement factories. This different summarized in table 2 below: 
Table 2 ICT facilities and availability with work place

\begin{tabular}{|c|c|c|c|}
\hline Statements & Place & Indicators & Value \\
\hline \multirow{4}{*}{ Internet connection in work place } & \multirow[t]{2}{*}{ Dire Dawa national } & Yes & 67 \\
\hline & & No & 12 \\
\hline & \multirow[t]{2}{*}{ Ture } & Yes & 8 \\
\hline & & No & 34 \\
\hline \multirow{4}{*}{ Storage of data in work place } & \multirow[b]{2}{*}{ Dire Dawa national } & Electronic & 52 \\
\hline & & Manual & 22 \\
\hline & \multirow[b]{2}{*}{ Ture } & Electronic & 12 \\
\hline & & Manual & 32 \\
\hline \multirow{4}{*}{ Access of electronic data in work place } & \multirow[b]{2}{*}{ Dire Dawa national } & Yes & 56 \\
\hline & & No & 16 \\
\hline & \multirow[t]{2}{*}{ Ture } & Yes & 22 \\
\hline & & No & 26 \\
\hline
\end{tabular}

According to Table 2 above respondents on the availability of Internet connection, storage of data and access of electronic data was varying in the respondents' work place. Internet connection, storage of data and access electronic data has the value $(67,8),(52,12)$ and $(56,22)$ respectively. The finding shows that 67 respondents from Dire Dawa national were says Internet is available in the office and only 8 respondents said that Internet connection was available in the office from Ture cement factory.

The storage and accessibility of electronic data in the case of Dire Dawa national and Ture cement factories was $(52,22)$ and $(12,32)$ respectively, this also shows usability and accessibility of electronic data is different in both factories. In Dire Dawa national Internet connection was fully functional and data was stored in electronic format and majority of the employees' access electronic data. In the case of Ture cement factory Internet connection was available in some office but not fully functional and most data were stored in manual form or use both electronic and manual storage mechanisms. In the case of an employee's skill of access electronic data, in most cases top managers accessed computerized data, but the majority of employee's access data in the form of hardcopy.

From the overall majority of the respondents had access computerized data from Dire Dawa national and in both factories ICT facility with Internet connection has great contribute for organizational productivity

The following statement identifies attitude of respondents through the survey questionnaire whether they agree or disagree based on the survey statement. Table 3 present the respondents perception on whether social community is used to share relevant information, employees' access and used knowledge saved in the system and get the address of the factory's employees from computer. Summaries of the respondents' response on the above statements are presented in table 3 below:

Table 3 Respondent satisfaction level on ICT facility

\begin{tabular}{|c|c|c|c|c|c|c|c|c|c|c|}
\hline \multirow{3}{*}{$\begin{array}{l}\text { SN } \\
1\end{array}$} & \multirow{3}{*}{$\begin{array}{l}\text { ICT indicator } \\
\text { Getting the address of } \\
\text { factory employees from a } \\
\text { computer, who can help } \\
\text { when doing work }\end{array}$} & \multicolumn{5}{|c|}{ Level of satisfaction } & \multicolumn{4}{|c|}{ central tendency } \\
\hline & & 1 & 2 & 3 & 4 & 5 & Mean & Med. & SD & Dec \\
\hline & & $13.6 \%$ & $32.2 \%$ & $16.1 \%$ & $33.1 \%$ & $5.1 \%$ & 2.83 & 2.0 & 1.17 & $\mathrm{U}$ \\
\hline 2 & $\begin{array}{l}\text { Social } \\
\text { communities(network) of } \\
\text { interests are used to share } \\
\text { relevant information related } \\
\text { to work }\end{array}$ & $0.8 \%$ & $27.5 \%$ & $16.7 \%$ & $50.0 \%$ & $5.0 \%$ & 3.30 & 3.0 & 0.95 & $\mathrm{U}$ \\
\hline 3 & $\begin{array}{l}\text { Employees are encouraged } \\
\text { to access and use knowledge } \\
\text { saved in systems. }\end{array}$ & $5.0 \%$ & $32.5 \%$ & $14.2 \%$ & 40.8 & $7.5 \%$ & 3.13 & 2.0 & 1.10 & $\mathrm{U}$ \\
\hline 4 & $\begin{array}{lr}\text { Computer } & \text { program or } \\
\text { software that performs } \\
\text { routine work operations or } \\
\text { automates } & \text { business } \\
\text { processes. } & \end{array}$ & $6.0 \%$ & $31.5 \%$ & $40 \%$ & $15 \%$ & $7.5 \%$ & 3.0 & 3.0 & 1.38 & $\mathrm{U}$ \\
\hline
\end{tabular}

Scale: 1=Strongly Disagree (SD), 2=Disagree (DA), 3= undecided (U), 4=Agree (A), 5=Strongly Agree (SA), $\mathrm{SDv}=$ standard deviation

Table 3 above present the distribution of respondents perception with regarding to ICT facility in Dire Dawa national and Ture cement factories, it showed that the decision was neither undecided nor disagree but close to undecided on the given statements that is social communities are used to share relevant information with 2.83 
mean value, most of the respondents use social community for share relevant data and new information with other employees but there are employees that is not use social network in their work place. Everyone get the address of factory employees from a computer when they needed their support and employees access and use knowledge saved in the system was another indicator of ICT facility in the factories with the mean value 3.30 and 3.13 respectively.

The decision of those indicator was neither undecided nor agree but close to undecided. From this employees work in Dire Dawa national and Ture cement factories get another support when they needed affect by organizational factors.

About employees accessed and used data that store in the system for facilitate product improvement, the result of this study also reflected that encouraging employees to use available knowledge in the system give power to employees and the products they produced, using knowledge available in the system facilitate factory product. The respondents' decision was neither undecided nor agree but close to undecided indicates, even if factories encourage employees to access and use knowledge save in the system there are situations that hindered like non functionality of computers are affect employees not access available knowledge from the system.

Another very importance respondents opinion on "computer program or software that performs routine work operations or automates business processes" with the same value of mean and median 3.0, the decision of respondent opinion was undecided, both in Dire Dawa national and Ture cement factories respondents does not have clear idea about soft ware for the purpose of facilitate product improvement.

The researcher explain about the respondents answer on ICT facility inside the factories and the contributions of ICT for organizational productivity and cheek the question is there a relation between ICT facility and organizational productivity by Pearson correlation. These correlations are summarized in table 4 below.

Table 4 Pearson correlation between ICT facility and organizational productivit

\begin{tabular}{|c|c|c|c|c|}
\hline & $\begin{array}{l}\text { ICT } \\
\text { facility }\end{array}$ & Internet connection & Storage of data & $\begin{array}{l}\text { Access electronic } \\
\text { data }\end{array}$ \\
\hline ICT facility & & $\begin{array}{l}.474 * * \\
.000\end{array}$ & $\begin{array}{l}.165^{*} \\
.013\end{array}$ & $\begin{array}{l}.300 \\
.000\end{array}$ \\
\hline Internet connection & $\begin{array}{l}.474 * * \\
.000\end{array}$ & - & $\begin{array}{l}.254 * * \\
.000\end{array}$ & $\begin{array}{l}.431^{* *} \\
.000\end{array}$ \\
\hline Storage of data & $\begin{array}{l}.165^{*} \\
013\end{array}$ & $\begin{array}{l}.254 * * \\
.000\end{array}$ & - & $\begin{array}{l}.211^{* *} \\
.000\end{array}$ \\
\hline Access electronic data & $\begin{array}{l}.300 * * \\
.000\end{array}$ & $\begin{array}{l}.431^{* *} \\
000\end{array}$ & $\begin{array}{l}.211 * * \\
.002\end{array}$ & \\
\hline
\end{tabular}

** Correlations is significance at the 0.01 level (2- tailed)

* Correlations is significance at the 0.05 level (2- tailed)

On the above table 4, the researcher wants to identify weather ICT facility has relationship with organizational productivity and answer the question is there a relationship between ICT facility and productivity? The answer is yes ICT facility has positive relation with productivity because ICT facility has positive relationship between storage of data and access electronic data with $.000 \mathrm{sig}$. values.

Internet connection also has positive relation between storage of data and access electronic data with $.000 \mathrm{sig}$. values, so ICT was the key and create smooth work environment inside the organizational.

In both factories ICT facility and Internet connection has great impacts on employees work environment, factories have those facility employees were easily stored data in electronic format and access those data when they need. All those relationships have positive indicates there is no ICT facility in the factories, there is no data in electronic formats but those relation has positive also positive impact on organizational productivity so, ICT facility has relationship with productivity.

\section{Existing policy in Dire Dawa and Ture cement factories}

Another way of examining knowledge management practice for product improvement were by examining existing policy in Dire Dawa national and Ture cement factories, to determine employees' knowledge about existing policy in the factories by asking different questions. The respondents answer was depending on their levels of understanding by giving choosing. Summaries of the respondents response is presented in Figure 4.1 below: 


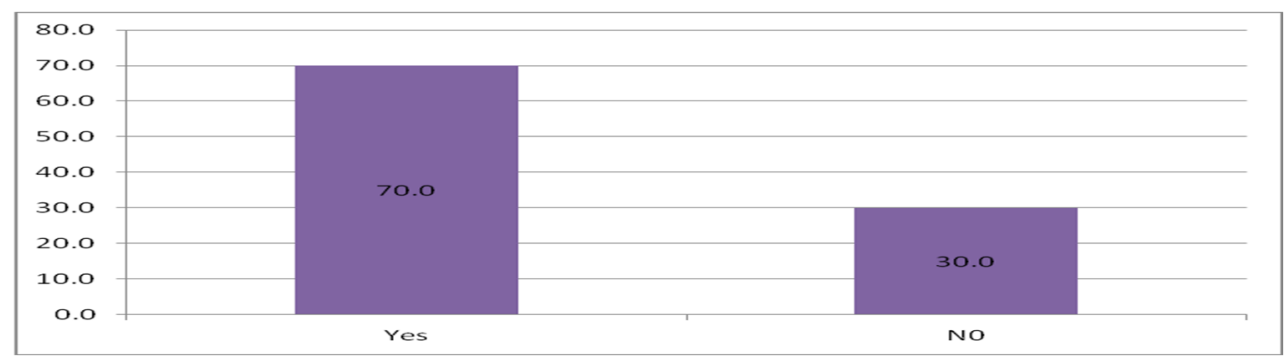

Figure 4.1 availability of knowledge management policy

The above figure shows $84(70 \%)$ of respondents answer knowledge management policy was available and functional both in Dire Dawa national and Ture cement factories but the current situation on availability of this policy show there is different in employees work place.

Knowledge management policy is also different in Dire Dawa national and Ture cement factories. This different respondent response rate is summarized in table 5 below:

Table 5 Existing KM policies with employees' work place

\begin{tabular}{|l|l|l|l|}
\hline Statement & Work place & Indicator & Value \\
\hline \multirow{4}{*}{ Knowledge management policy } & Dire Dawa national & Yes & 58 \\
\cline { 2 - 4 } & & No & 12 \\
\cline { 2 - 4 } & Ture & Yes & 12 \\
\cline { 2 - 4 } & & No & 32 \\
\hline
\end{tabular}

The above table 5 shows, there is a difference in employees' workplace with knowledge management policy $(58,12),(12,32)$. This implies that knowledge management policy was directly difference with employees' work place, in Dire Dawa national there was functional written ICT policy collaborating with knowledge management policy that contributed to organizational productivity, but in Ture the process of knowledge management was culture without any clear written knowledge management and ICT policy document but knowledge management takes place with the base of factory policy and principle. This shows even if factories have written knowledge management policy or not knowledge management practice was processed inside the factories at any time and knowledge management practice was the base of product improvement in Dire Dawa national and Ture cement factories.

Mistake correction methods, employees work motivation methods and update employees work profession are indicators of existing organizational policy in both Dire Dawa national and Ture cement factories. Summaries of the respondents response is presented in table 6 below:

From the below Table 6, according to respondents there are other functional policy availability in Dire Dawa national and Ture cement factories, "giving educational chance" was one of organizational policies to improve employees work motivation 53(43.7\%) followed by "giving additional money for employee "43(36.1\%).74(61.7\%) of respondents show "attending workshop" was the way of employees use to improve work profession followed by" taking short term training" $28(23.3 \%)$, from this in both factories, has impact on product improvement and employees need to update their own profession, workshop was the way to update their own profession for employees.

Dire Dawa national and Ture cement factories have cultural policy that correct employees mistake, the respondents answered show both factories use "discussed about the issue" $72(60.5 \%)$ followed by the "use the mistake as sample" $26(21.8 \%)$ was us problem solving mechanism. According to both factories trend discussing the issue and use the problem as a sample in managerial level, then take measurement according to their mistake and worker proclamation was the main problem solving mechanism.

Table 6 different organizational policy

\begin{tabular}{|c|c|c|}
\hline Activity & Frequency & Percent \\
\hline \multicolumn{3}{|l|}{ Mistake correction methods } \\
\hline Discussed about the issue & 72 & 60.5 \\
\hline Fire employee that makes a mistake & 16 & 13.4 \\
\hline They use as a sample & 26 & 21.8 \\
\hline Others & 6 & 4.3 \\
\hline Total & 120 & 100 \\
\hline \multicolumn{3}{|l|}{ Employees work motivation methods } \\
\hline Giving additional money & 43 & 36.1 \\
\hline Giving educational chance & 53 & 43.7 \\
\hline Giving managerial position & 24 & 20.2 \\
\hline Total & 120 & 100 \\
\hline
\end{tabular}




\begin{tabular}{|c|c|c|}
\hline Activity & Frequency & Percent \\
\hline \multicolumn{3}{|c|}{ Update employees work profession } \\
\hline Attending workshop & 74 & 61.7 \\
\hline Taking short term training & 28 & 23.3 \\
\hline Attending meeting & 17 & 15 \\
\hline Total & 120 & 100 \\
\hline
\end{tabular}

Respondents' level of satisfaction was another way of examining available existing policy inside the factory to improve productivity in Dire Dawa national and Ture cement factories. Table 7 summarized level of respondents satisfaction, according to the statement on knowledge sharing practices contribute organizational productivity of the factory, decrease cost of production, functional policy regarding to knowledge sharing among employees for better Product and Factory has a policy regarding databases of good work practices are regularly updated with the rule mean value line between 3 to 3.49 close to 3 that means Des. was undecided and the mean value line between 3.5 to 4 close to 4 that also shows the Dec. was agree. The responses given by the respondents are summarized in table 7 below

Table 7 existing organizational policy

\begin{tabular}{|l|l|c|l|l|}
\hline SN & Organizational existing policy & \multicolumn{3}{|c|}{ Central tendency } \\
\cline { 3 - 5 } & & Mean & SD & Dec. \\
\hline 1 & $\begin{array}{l}\text { Knowledge sharing practices contribute organizational productivity of } \\
\text { the factory and decrease cost of production. }\end{array}$ & 3.3529 & 2.07031 & $\mathrm{U}$ \\
\hline 2 & $\begin{array}{l}\text { Functional policy regarding knowledge sharing among employees for } \\
\text { a better product }\end{array}$ & 3.2833 & 2.16809 & $\mathrm{U}$ \\
\hline 3 & $\begin{array}{l}\text { The factory has a policy regarding databases of good work practices are } \\
\text { regularly updated. }\end{array}$ & 3.2017 & 2.20437 & $\mathrm{U}$ \\
\hline 4 & The policy in my factory work on writing documentation. & 3.5370 & 2.01379 & $\mathrm{~A}$ \\
\hline 5 & $\begin{array}{l}\text { Encourages workers to participate in project teams with internal and } \\
\text { external experts }\end{array}$ & 3.6261 & 2.13909 & $\mathrm{~A}$ \\
\hline
\end{tabular}

Table 7 discussed the value of serving individual about the overall existing policy of the factories. "knowledge sharing practices contribute for organizational productivity of the factory and decrease cost of production" the respondents decision indicate neither undecided nor agree with mean value 3.3529 but close to undecided shows that in both factories employees does not have equally understanding about knowledge sharing practice contribution on organizational productivity of the factories. Respondents opinion (decision) on "functional policy regarding to knowledge sharing among employees for better product" with the mean values 3.2833 was neither undecided nor agree but close to undecided. This shows employees in both factories doesn't clearly know about knowledge management policy and ICT policy also knowledge sharing policy is not work in both factories because in Ture cement factories knowledge sharing is culture not policy.

"Policies regarding to databases updating" is another policy exercised by employees in both factories. The statement has respondents decision with mean values 3.2017 is neither undecided nor agree but close to undecided indicate policy regarding to databases of good work practices were regularly updated but this policy is not work in both factories equally or all employees work in both factories does not have equal understanding about data base, some respondents decision about knowledge available in the system always updated and database always has up-to-date information/knowledge, this up-to-date knowledge needed or positive impact on factory productivity.

In another way" policy in the factories depends on written document that is available and legal" was another indicator of organizational policy, perversely this research shows electronic document, written document and employees were sources of knowledge in both factories and the base of organizational policy by the mean value 3.53 with respondents' decision neither undecided nor agree but close to agree. Respondents' opinion on "encouraging workers to participate in project teams with internal and external experts" has the mean values 3.6261 indicates that majority of respondents decision was neither undecided nor agree but close to agree by factories encourage participant in project with internal and external trainer that is important for productivity in Dire Dawa national and Ture cement factories and both factories use those trends as employees work motivation mechanism.

\section{Results of qualitative data}

Manufacturing industry continue to do more with less, employing lean and agile techniques to optimize operations and maximize product availability. Manufacturing leaders also satisfy shifting customer and regulatory requirements, drive product and process innovation and anticipate the impact of potentially disruptive technologies on their business and operating models. The researcher also carried out interviews and observation in Dire Dawa national and Ture cement factories' managers, MIS/HR and ICT director, on the availability of knowledge management practice, ICT facility and organizational policy for product improvement. 
Interview were done to strengthen the qualitative data collected using structured questionnaire about respondents ICT facility and knowledge management policy to improve organizational productivity in Dire Dawa national and Ture cement factories. According to the respondents' ICT facility, the availability of knowledge management practices, the culture of organization and existing policy have relation with knowledge management practice and facilitator of organizational productivity. In both factories the interviewees indicated that there were ICT facility in an employee's office, in addition, interviewee from Dire Dawa national said that the system was networked and semi-automated based on the department need, according to her, if employees need any information from top managers, they get from their computer, even if Internet connection does not work all computers were connected to each other via Intranet and communication is never disconnected. Moreover, communication web mail, Gmail chat and techno blorth were way of communication in Dire Dawa national. Techno blorth is one of the communication ways in Dire Dawa national, this use as social communication and functional on local area network. This technology is functional with Internet connection and without Internet connection by pop up message.

Respondents from Ture even they have ICT facility in their offices, however Internet connection is not fully functional, according to him the factory data base, server or main program protected by Chinese and he also says the programming language is work by mandarin language, this create a problem on employees work. According to respondents from Dire Dawa national and Ture cement factories data were stored in electronic form and majority of the employee's access electronic data.

According to the interviewees result, the benefit of ICT such as facilitating works in each office and create good work environment, manage work, control over all systems and facilitate system functions were the main responsibility of ICT office in both factories. Moreover, knowledge base system (KBS) was available in Dire Dawa national cement factory for decision making purpose, any decision in the factory was supported by KBS. Web long, Clinic system, safety encapsulations and document repository were some of the decision mechanism supports by the KBS in the case of Dire Dawa national. Regarding to the above issue, according to Ture cement factory respondents not such system available but they have a plan to create a system that facilitates productivity.

Respondents in both factories said that improve in product and service quality, transparency and productivity were the major outcomes of knowledge management practice. In Dire Dawa national there were responsible offices for knowledge management practice by position of ICT director, the same is true in Ture cement factory there was no official office for knowledge management practice and ICT, but the work is done by quality control officers or the office of quality controls was responsible for knowledge management practice and ICT. Dire Dawa national and Ture cement factories have organizational culture to facilitate educational chance, training outside country, to give allow Gmail account (phone card) are the way of incentive mechanism to motivate employees in the work place.

In Dire Dawa national cement factory there were a written ICT policy with collaborate with knowledge management policy, but in Ture cement factory there is no any clear written ICT and knowledge management policy, but they are working related to worker proclamation, factory principle with knowledge management as a culture. In Ture cement factory like knowledge sharing exercise as a culture and policy like mistake correction methods work based on worker proclamation.

Shortage to knowledge management expert, shortage of ICT facilities, most employees work on ICT is not professionals, shortage of protecting offices and uncomfortable work environment were the major problem raised by respondents from Ture cement factory. In the case of Dire Dawa national cement factory, the process takes time, the expensiveness of materials used for ICT facilitating and responses of employees for the system were the main problems. Building fully automated system and builds a smart work environment were the future plans of Dire Dawa national cement factory, similarly building a full network environment, build KBS for decision making purpose and show big image on the world by increasing productivity and quality of product were the future plans of Ture cement factory.

\section{Discussion}

The contributions of ICT facility for productivity in Dire Dawa national and Ture cement factories

The study found that availability of computer and internet connection that the opinion of the employees' response was differs, ICT service that was the availability of computer, internet connection, storage and accessibility of computerized data. From the total respondents 95 respondents answers "there is ICT facility" in their office and from the total 74 respondents also answers Internet connection was available in their office. In Dire Dawa national more than $80 \%$ office have full of ICT facility and Internet connection but in Ture almost $60 \%$ office have full of ICT facility and Internet connection. Dire Dawa national and Ture cement factories use social network for knowledge sharing purpose, the main knowledge sharing mechanism inside and outside the factories was social network like group mail, face book, twitter, linkeId and pinterest, for all the above social network were bloke inside the factories that means except face book the other social network work inside the factories. Any employee work in Dire Dawa national cement factory was not exchange information from outside world except ICT directors 
allow the permission.

The main use of social network was distribute large knowledge or information at the same time to all employees and people in the world, in both factories face book was block in all time but both factories has face book page for sharing knowledge or information that is available in the factories for outside world by ICT director. In Dire Dawa national group mail and pop up remainder were key electronics knowledge sharing mechanism inside their factory, similarly in Ture cement factory group mail and e-mail were the main electronic knowledge sharing mechanism use within the factory. Even if ICT facility is not full in both factories, they use ICT for product improvement and increase organizational productivity.

The research article reviewed by Stephan Kudyba, 2003 indicated a well-designed document repository with portal access helps spread the available captured knowledge and experience existing within the firm to those in need of this information. According to his study other IT attributes such as search engines in some initiatives also augment the process of retrieving vital documentation or expert contacts. Even simpler IT systems such as e-mail and online internal chat systems facilitate informal networking channels for employees to correspond and share experiences, information and knowledge which can help reduce redundancy of errors and lead to innovative techniques for processes and product development. According his result majority of the respondents identify the importance of ICT for productivity that is ICT as a medium or channels of communication was a very useful tool, it saves time and enhances the speed of correspondence and decrease the reaction time and it is also minimizing errors. The use of ICT was to improve their work performance and the main benefit of internet connection was to share available data easily and in secured way, this is the means of improving productivity, if using strategically.

The idea of the current study supports by Tayyab (2003) who investigated the role of ICT in improving productivity. ICT was serving as tools for provoking and stimulation collaboration among constructors and sub contractors over which the philosophies of knowledge management and supply chain management have been built by implementing ICT with knowledge management and to exploit them to their best for the industry productivity and profitability.

ICT also has its own impact on cement industry; the another research was done by the role of ICT in cement industry by (Fidelis ,2012). His finding indicated that ICT has greatly improved corporate performance of cement manufacturing industry and the relationship between investment in ICT by cement manufacturing industries and their productivity trend is positive. The current studies also show there were positive relations between ICT facilities with organizational productivity by .000sig. value. Nicholas (2003) study result agrees with the current research result that was the benefits of ICT were identify through its role as a sector, one through allowing new sectors and through overall improvements.

\section{Existing policy on knowledge management in Dire Dawa national and Ture cement factories}

Manufacturing industry identifies knowledge management policy and the major important to apply knowledge management practice for improving productivity was to know about policy that was available in the factories and use that policy. ICT policy collaborate with knowledge management policy was available in Dire Dawa national and Ture cement factories this policy in the form of written or culture. Dire Dawa national have written ICT policy collaborate with knowledge management policy, in the case of Ture ICT policy collaborate with knowledge management policy was culture there was no clear written document for exercising ICT and knowledge management practice. Giving educational chance was the major principle that both factories use for increase employee work motivation and innovation mechanism. Majority of respondents were agree by availability of knowledge management practice with policy has great impact on organizational productivity. Except ICT and knowledge management policy most policies available in both Dire Dawa national and Ture cement factories were similar and they use for organizational productivity. Knowledge management visualizes capturing, creating, sharing and managing knowledge.

ICT policy collaborate with knowledge management policy in Dire Dawa national cement factory comprises of different components like people who create, share and use knowledge as part of their daily work and help shape a knowledge sharing organizational culture, processes which include methods to acquire, create, organize, share and transfer knowledge to fit different situations and technology including mechanisms to store and provide access data, information and knowledge that must be integrated with the way people work and address their real needs of employees. ICT policy collaborate with knowledge management policy easily facilitate the process of knowledge management practice in Dire Dawa national cement factory, in the case of Ture cement factory those the process of knowledge management practice like knowledge creation, knowledge capture, knowledge sharing was available but there is no clear and written ICT policy and knowledge management policy. Employees were loyal for factory principle and worker's proclamation, every activity in Ture cement factory work on the base of organizational principle and worker proclamation. The main problem with the non availability of knowledge management policy was the issue of security and intellectual right of knowledge creator /invention inside the factory.

Knowledge management practice in Dire Dawa national and Ture cement factories was the base of 
productivity, increase business process achievement and service improvement was the contributions of knowledge available in the factories. Product and service quality, strategy formulation process, communication and knowledge transparency were the major output of knowledge management. Effectiveness, productivity and profit were benefit of knowledge management in both factories. The current study agrees with the study of Herkema (2003), who addressed the process of knowledge acquired, adapted and shared with the aim to create new knowledge which improve product and service was consider the innovation process. For increasing organizational efficiency, key decision making as to resource allocation was a prime requisite; knowledge management initiative was no exception. According to his result knowledge management initiative was a strategic plan that seeks to develop and utilizing the existing assets of knowledge and experience of individuals within an organization in order to enhance business process.

The finding of the current study also agrees with the finding of Kiessling (2009), on exploring knowledge management to organizational performance in a transitional economy. Kiessling found that direct effect of knowledge management was on the outcome, creativity, products, and service improvement and employees development of the organization.

Knowledge management was found to have a direct relationship with productivity of the organization. The current study of knowledge management practice has direct relationship with productivity and policy, technology and people or leadership system that was the facilitator of knowledge management practice on organizational productivity. The researcher wants to answer the question "Is there relationship between available knowledge in the factories and organization productivity, Is there relationship between ICT facility and organizational productivity and Is there relationship between knowledge management practice and organizational productivity" the answer was "yes" there is negative, moderate and positive relation by $91 \%$ respondents answer with .000 sig. values.

The current study show knowledge management practice have relation with productivity, by this reason the study disagree with the work of Amir 2012 who reported that there is no meaningful relationship between knowledge management practice and productivity, because of the degree of utilization of policy and approach, leadership systems, promotion and bonus system, knowledge acquisition system, knowledge training system were less than standard average.

According to his result policy and approach, leadership systems, promotion and bonus system, knowledge acquisition system is not directly affect the factory knowledge management practice and the contribution is not clear on organizational productivity but in the current study those things were affect knowledge management practice in the factories and affect organizational productivity.

\section{CONCLUSION AND RECOMMENDATION CONCLUSION}

The study showed that Cement factories need ICT facility for their production process, today everyone has interest to work with technology in their offices, but storage and accessibility of electronic data in the case of Dire Dawa national and Ture cement factories were different. Currently both factories use its' own available technology for increase organizational productivity.

The main thing in those factories was using social networks for exchange information like Gmail, Gmail chat and pop up message, Face book was not working inside both factories because it is block but ICT directors share information about the factory product, service, price and organizational information for people that live outside the factory at any time. Enhancement of product and service quality, strategy formulation process, increase production, better communication, knowledge transparency, increase market share, ease collaborative work of virtual teams and better decision were the major outcomes of knowledge management in Dire Dawa national and Ture cement factories. Knowledge management practice was available with ICT infrastructure in both Dire Dawa national and Ture cement factories. Moreover, knowledge transferring and knowledge sharing were common practices in those two factories and exercised in day to day employees' activity.

The main interesting find in this research was knowledge sharing practice was functional with and without written policy, in Dire Dawa national knowledge sharing work depend on ICT policy collaborate with knowledge management policy but in Ture knowledge sharing hasn't any clear written ICT or knowledge management policy but work as a culture, it depend on worker proclamation. The relation between productivity with available knowledge in their factories depends on people, ICT facility, existing policy, organizational and knowledge management culture that were available in the factories. The study also concludes currently both cement factories have two environment those were knowledge management processes and business process environment, this two environment works separately. Similar case the present proposed framework creates a link or collaboration between those two environments.

\section{Recommendations}

A more immediate and productive area of policy development was that of stimulating diffusion of quality 
knowledge to the cement factories community, through various bodies and mechanisms. These might include the support of business networks, development and KBS or knowledge portals especially for Ture cement factory, so managers of Ture cement factory give attention and facilitate this in their work place.

An increased understanding the role of knowledge and knowledge management practice for those types of manufacturing industry in particular will most probably lead to good returns in productivity and social benefits. Both factories create knowledge center and introduced the use and available good practices in their factories.

Dire Dawa national cement factory work with ICT policy instead of knowledge management policy related with factories vision and mission, to achieve this objective factories give attention for employee's profession and work on introducing knowledge management policy clearly and knowledge sharing was highly variable, differentiated and culture in Ture cement factory, Therefore managers of Ture cement factory should set written knowledge management policy for further work and work on employees work profession and educational statues.

Effective knowledge management policy helps an organization adjust quickly its business processes in accordance with current conditions, which especially becomes noticeable in times of frequent and dynamic changes. Efficient knowledge management enables employees to use knowledge, and other resources more efficiently, both factories create efficient knowledge management enables in the facility.

ICT facilities or technology was the base of factory production process and organizational productivity, managers of Ture cement factory established its own knowledge management and ICT office and assign knowledge expert and Dire Dawa national concern on knowledge management expert for easy work.

In both factories, education was the base of organizational productivity and everyone in their factories needs to learn, so organization more work on culture of education and creates educational competitiveness between employees.

\section{Reference}

Abhary, A., Adriansen, H. K., Begovac, F., Quin, B., Spuzic, S., Wood, D., Xing, K. (2008), some aspects of defining knowledge. http://epistemic.synthasite.com/ (accessed 11th November 2008).

Adish Kumar.(2006), Survey of knowledge management practices in Indian manufacturing industries, Journal of Knowledge Management, Vol. 10 Iss: 6, pp.110 - 128.

Darroch, J. and McNaughton, R. (2002), Examining the link between knowledge management practice and types of innovation, Journal of Intellectual Capital, Vol.3, No.3, pp. 210-222.

Fischer, Ulli; et. all;(2000) System Concept, The project PICK (IST-1999-10442), improvement in manufacturing companies e-Business and eWork Conference, Public report Madrid, October 2000.

Fugate, B.S., Stank, T.P. \& Mentzer, J.T. (2009). Linking improved knowledge management to Operational and organizational performance, Journal of Operations Management,2009.

Jain, P. (2007). An empirical study of knowledge management in academic libraries in East and southern africa. library review 56(5): 377-392.

Martin, B. (2008), Knowledge management, annual Review of information science and technology (ARIST) 42.

Martin, V. A. et al. (2005). Cultivating knowledge sharing through the relationship management Maturity model, The Learning Organization, Drivers, and Performance Implications.

Mosoti, Z., \& Masheka, B. (2010). Knowledge management: the case for Kenya. The journal of language, technology \& Entrepreneurship in Africa. 2 (1)

Leonard-Barton, D. (1995), the Wellsprings of Knowledge. Cambridge, MA: Harvard Business School Press, 1995.

Wah, L. (1999b), making knowledge stick', Management Review, May, pp. 24-9.

Webster, M. (2007), the role of library in knowledge management, Knowledge management social cultural and theoretical perspectives. Ed. R. Rikowski. Oxford: Chandos publishing; 77-91.

Wormell, I. (2004). Skills and competencies required to work with knowledge management and libraries, Ed. H.E. Hobohm Munchen: Saur: 107-114,2004. 